https://doi.org/10.48009/1_iis_2006_389-393

\title{
THE (R)EVOLUTION OF SYNCHRONOUS COMMUNICATION IN DISTANCE EDUCATION
}

\author{
Joseph Rene Corbeil, The University of Texas at Brownsville, rene.corbeil@utb.edu
}

\begin{abstract}
With the level of synchronicity now available to virtually anyone with access to a telephone and a computer, one would expect that the technology that revolutionized the way businesses communicate, would also find its way into distance education programs. However, due to the current commitment to educational convenience that has been institutionalized in asynchronous distance education programs, little, if any, progress in integrating audio and videoconferencing tools into distance education has been made. One could argue that distance education is in the midst of a communications revolution that is in search of a cause.
\end{abstract}

Keywords: Distance Education, Video Conferencing, Synchronous Communication

\section{INTRODUCTION}

When desktop videoconferencing technologies made their debut in the mid 1990s, it appeared that webbased distance education was on the verge of a major communications revolution. However, after a brief period of experimentation, desktop videoconferencing was abandoned by most distance education providers before it had a chance to fully evolve. Initial tests were plagued by setbacks including expensive hardware and software, poor frame rates and audio reception, jerky or frozen images, limited bandwidth, limited capabilities, and incompatibility issues. As asynchronous web-based distance education programs flourished, synchronous programs faded.

However, within the past five years, several key technological issues have been resolved, making synchronous communication less expensive, more powerful, and available to more people. This renewed viability suggests that distance educators give desktop videoconferencing a second look.

Regenold [9] suggests that a videoconferencing revolution is just over the horizon and lists several indicators:

(1) IP-based videoconferencing is on the rise. In 2001, ninety-five percent of videoconferences were delivered over ISDN networks. In 2004, more than twenty percent of group videoconferences and ninety-two percent of individual videoconferences were IP-based. IP advantages include lower cost, better data sharing capabilities, and videoconferencing integration with desktop computers.

(2) Videoconferencing is shifting from AV to IT. With companies managing videoconferences on their own IP networks, audiovisual equipment is slowly being replaced by computer-based technologies. This shift has caught the attention of companies like Microsoft, Avaya, and Cisco-all of which have videoconferencing products.

(3) Personal use of desktop videoconferencing is on the rise. A significant and noticeable trend has been the rise in desktop videoconferencing technology for personal use. The surge in interest and development over the past year shows a significant maturation of the desktop videoconferencing industry.

(4) Web conferencing quality is improving. While web conferencing is still no substitute for a high quality video conference, overall sound and video quality is steadily improving. New applications, including polling tools, chat features, and whiteboards are making web conferencing programs more interactive.

\section{From Revolution to Evolution}

A revolution is a drastic and far-reaching change in ways of thinking and behaving. If the change is slow, gradual, or progressive it is called evolution. Sometimes, new ideas are inhibited by established norms or a lack of vision. Take, for example, the invention of the printing press. It took several years for the early printers to realize that this new technology also brought with it new possibilities. Instead of trying new things, the early printers used the printing press to mimic the handwritten manuscripts to which they were accustomed. They did not realize until many years later that by using smaller fonts, they could reduce costs and printing time, thereby making printed materials more affordable and accessible. Since its invention, the printing press has revolutionized (and led to the 
creation of) many industries, including the news, marketing, and publishing industries.

In much the same way, desktop videoconferencing has the potential of revolutionizing the way distance education courses are delivered. However, due educational convenience, asynchronous communication has been institutionalized into the vast majority of web-based distance education programs. Nevertheless, according to Haefner [4], asynchronous and synchronous communication can work symbiotically in most online classes. In an opinion paper titled The Importance of Being Synchronous, Haefner wrote:

It is hard to imagine teaching without both these modes of interacting with our students, and I can't believe many teachers would want to handicap their teaching by relying on just one of them. But anecdotal evidence suggests many online teachers do exactly this, and rely almost exclusively on asynchronous communication... Computer-aided instruction that is solely asynchronous cannot possibly convey any kind of immediacy. If it takes days, or even hours, for students to get a response to a question, many students will lose the intellectual thread - and the urge to follow it. (II 5)

Although a variety of synchronous communication tools like chat, desktop video conferencing, and voice over IP have been in use by individuals and businesses for years, asynchronous communication has continued to dominate the DE scene. The time has come for us to give synchronous communication a second look to determine how it can contribute to distance education, establish how it should be integrated into a coherent online pedagogy, and justify the rationale for supporting it in distance education courses. From interesting experiment to exciting frontier, desktop videoconferencing is quietly moving from revolution to evolution.

\section{The Right Tool at the Right Time}

There are many advantages and disadvantages to synchronous and asynchronous communication. According to Regenold [9], the key to successful implementation is knowing when to use the right tool at the right time for the right purpose.

Synchronous tools enable real-time communication and collaboration in a "same time-different place" mode [1]. These tools allow people located in different places to come together simultaneously. However, the principal drawback of synchronous communication is that it requires "same-time" participation. Different time zones and conflicting schedules can create communication challenges.

Asynchronous tools enable communication and collaboration over an extended period of time through a "different time-different place" mode [1]. Asynchronous communication is useful for sustaining dialog and collaboration over a period of time and for providing resources and information that are instantly accessible. It allows individuals from multiple time zones and busy schedules to participate when it is convenient to them. In addition, communications are easily archived making it easy to share and distribute information. However, according to Haefner [4], this convenience and flexibility carries some serious liabilities, the chief one being a sense of disconnection and isolation.

Collis [2] identified four significant advantages of synchronous over synchronous systems:

- Motivation - synchronous systems focus the energy of the group

- Telepresence - real time interaction builds a sense of social presence and involvement and helps to develop group cohesion

- Feedback - synchronous systems provide quick feedback on ideas, and support consensus and decision making

- Pacing - synchronous events encourage people to keep up-to-date and provide a discipline to learning which helps people to prioritize their studies

Two additional obvious advantages can be added to this list:

- $\quad$ Spontaneity - synchronous events make it easy to add new ideas to the conversation, brainstorming or decision making is well supported.

- Familiarity - synchronous systems can simulate a more traditional environment.

Although the vast majority of distance education programs are entirely asynchronous, Collis [2] contends, the trend should be toward combining synchronous and asynchronous media in an attempt to capitalize on the benefits of both modes. If we accept Haefner's [4] assertion that synchronous and asynchronous communication can work symbiotically in online classes, then the challenge lies in finding ways to integrate synchronous communication into the asynchronous teaching model, thus preserving the flexibility and convenience of asynchronous communication while 
enhancing the overall efficiency and quality of communication through synchronous communication.

Effectively integrating synchronous communication into an asynchronous online environment requires structure and effective moderation of the discussions. As synchronous tools, videoconferencing and voice over IP can be used for one-to-one or one-to-many sessions. These sessions typically involve all participants being online simultaneously and interacting at the same time. Without time for reflection, some instructors have found it helpful to prepare students in advance by posting specific questions or content for them to consider prior to engaging in a live session [5]. As a one-to-one tool, many instructors consider desktop videoconferencing to be an effective tool for conducting virtual office hours, allowing them to be more responsive to individual student requests.

Here are some tips for effectively using synchronous communication for academic purposes:

- Be organized. Successful live sessions need to be planned carefully. Prepare a focused topic in advance for each session [10].

- Be flexible. Be ready to move in whatever direction the discussion may lead, but be prepared to redirect the conversation if it goes off-topic [10].

- Ensure time for interaction. Videoconferences should be run as seminars rather than lectures. Allot time for participants to ask questions from instructor and to converse amongst themselves [7].

- Inform learners of your expectations for how these tools will be used as part of the course [6].

- Outline the rules for participation in your syllabus (i.e., no harsh language, no belittling of their fellow classmates, keeping their comments relevant to the topic) [6].

- Decide what your objectives are for using synchronous communication. Determine how using these tools assist learners in achieving the overall goals of the course [6].

- Monitor the dialogue to keep it on topic. Consider the number of students that can be meaningfully involved in live discussions. Smaller groups tend to work better [5].

- Be aware of those who do not to participate. Determine if their nonparticipation is it due to a technological or skill problem. Try to find a way to draw non-participants into the discussion [5].

- Use audiovisuals when appropriate. Use a shared whiteboard to post pictures, graphs, charts, or PowerPoint presentations to help keep students focused. If no whiteboard is available, submit materials to students in advance and have them print them out to follow along.

- Summarize the major points at the end of each session.

- Prepare a contingency plan. Technical breakdowns can occur anytime. With a "Plan B," the whole class can have a piece of mind and enjoy the course [8].

\section{Choosing the Right Tool for the Job}

While there are many excellent video and audio conferencing programs and equipment on the market, it can be a formidable task to identify which product is most appropriate for a program's needs. Determining whether a product is worth the investment can be difficult and time-consuming. First and foremost, however, pedagogy should be the guiding consideration. Media or technology selection should coincide with the design and development of instructional activities, which are dictated by performance objectives or learning outcomes [8]. After that, the following issues and questions should be addressed in the selection of a videoconferencing product or solution:

- Cost. One time fee or recurring charges? Do you purchase the license outright or do you incur yearly renewal of service fees?

- Ease of Use. Is the program easy to install? Administer? Use? Will faculty and staff require training? Does the program have a user-friendly interface?

- Adaptability. Is the program adaptable to instructional use? Is the interface customizable?

- Scalability. Is the program scalable to permit multiple simultaneous sessions?

- Compatibility. Is the program compatible across multiple platforms and operating systems?

- Bandwidth Requirements. What are the minimum bandwidth requirements for receiving audio? Video? Both?

- Features. What communication features does the program have? Chat, IM, Whiteboard, Audio, Video, Polling?

- Benefits. What are the benefits of using one platform over all others?

- Limitations. What are the limitations of this platform?

- Necessary Accessories. What accessories are needed to promote the use of selected tools?

- Usefulness/Effectiveness. To what extent is the chosen tool found useful to student achievement?

- Quality. How visually pleasant is the target tool? 


\section{Students' Perceptions of Synchronous Communication}

In an informal survey of graduate students enrolled in an online class, two questions were asked:

(1) Which form of web-based communication do you feel is more efficient for facilitating group discussions?

(2) Which form of web-based communication do you prefer in your online courses?

Thirty-nine students participated in the survey. For Question \#1, twelve students $(30.8 \%)$ believed that asynchronous communication was more efficient than synchronous communication for facilitating group meetings while twenty-seven students (69.2\%) believed the opposite was true. Yet, in response to Question \#2, only 3 students $(7.7 \%$ ) responded that they preferred to communicate synchronously in their online courses as opposed to asynchronously. Despite the obvious perceived efficiency of synchronous communication over asynchronous communication, a clear majority (69.2\%) of students (36) responded that they preferred to communicate asynchronously in their distance education courses.

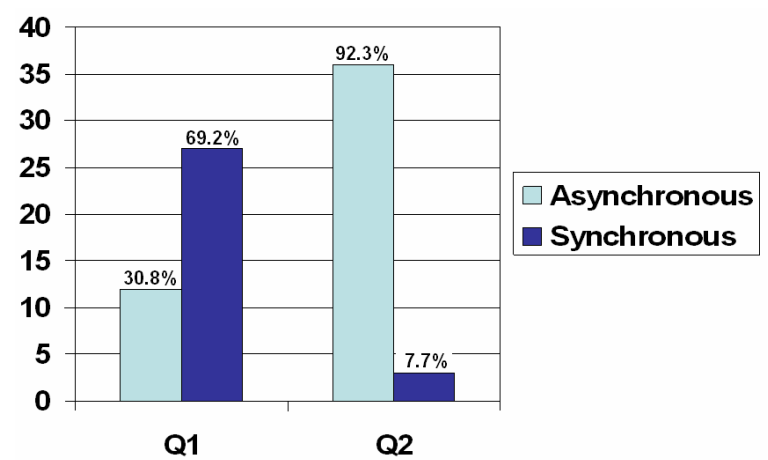

Figure 1. Results of survey on students preferences with regard to synchronous versus asynchronous communication in distance education courses.

This survey, although unscientific, illustrates a trend in distance education programs of emphasizing convenience over efficiency. Although students appreciated the efficiency of synchronous communication, they preferred the convenience that asynchronous communication afforded them. This dichotomy is understandable when one considers the needs of adult learners. On the one hand, they need and desire feedback and interaction between and among their peers and instructors. On the other hand, they also need flexibility and convenience to balance busy schedules to work around professional, family, and learning responsibilities. The results of this survey underscore the need to find a balance between synchronous and asynchronous communication in distance education programs, exploiting the benefits of both while minimizing their shortcomings.

\section{SUMMARY}

Clearly, in the evolving world of distance education, synchronous communication has a significant role to play. According to Ellis [3], while asynchronous communication continues to play an important role in providing instruction that is free of time, place and scheduling, the synchronous approach adds immediacy, live interaction and personal contact. This is endorsed by Wang and Newlin [11] who argue, "...asynchronous tools are viewed as the backbone and muscle for the subject content, whereas synchronous media...are the heart and hustle of online courses." Both systems can peacefully co-exist if care is taken to appreciate their relative strengths and weaknesses. Yet, as with all technology, care should be taken to match the technology to the learning objectives and attributes of the students [2].

\section{REFERENCES}

1. Ashley, J. (2003). Synchronous and Asynchronous Tools. Executive Update Online. Retrieved January 10, 2006, from the World Wide Web:

http://www.gwsae.org/executiveupdate/2003/De cember/beyond_sidebar.htm

2. Collis, B. (1996). Tele-learning in a digital world: The future of distance learning.

London: International Thomson Publications.

3. Ellis, B. (1997). Virtual Classroom Technologies for Distance Education: The Case for On-line Synchronous Delivery. DETAC Corporation. Retrieved January 10, 2006, from the World Wide Web: http://www.detac.com/solution/naweb97.htm

4. Haefner, J. (2000). Opinion: The Importance of Being Synchronous. Academic.Writing. Retrieved January 10, 2006, from the World Wide Web: http://wac.colostate.edu/aw/teaching/haefner200 0.htm

5. Ko, S. \& Rossen, S. (2001). Teaching online: A practical guide. Boston: Houghton Mifflin.

6. Lowe, L. \& Oughton, J. (2005). Moderating chats and facilitating discussions. Instructional Technology Resource Center, West Virginia 
University. Retrieved January 10, 2006, from the World Wide Web:

http://www.itrc.wvu.edu/openhouse/

7. Nayman, I. (1999). Lessons from a

videoconferenced course. CAUSE/EFFECT, 22(3). Retrieved January 10, 2006, from the World Wide Web:

http://www.educause.edu/ir/library/html/cem/ce m99/cem9930.html

8. Pan, C., \& Sullivan, M. (2005, September).

Promoting synchronous interaction in an

eLearning environment. T.H.E. Journal, 33(2), $27-28,30$.
9. Regenold, S. (2005, May). Can you see me now? Presentations, 19(5), 38-40.

10. Schwier, R. \& Balbar, S. (2002). The interplay of content and community in synchronous communication: Virtual communication in a graduate seminar. Canadian Journal of Learning and Technology, 28(2), 21-30.

11. Wang, A. Y., \& Newlin, M. H. (2001, August). Online lectures: Benefits for the virtual classroom. T.H.E. Journal, 29(1). Retrieved January 10, 2006, from http://www.thejournal.com/magazine/vault/A356 2.cfm 